\title{
Oral health of aboriginal people with kidney disease living in Central Australia
}

Kostas Kapellas', Jaquelyne T. Hughes ${ }^{2,3}$, Alan Cass², Louise J. Maple-Brown², Michael R. Skilton ${ }^{4}$, David Harris ${ }^{5}$, Lisa M. Askie ${ }^{6}$, Wendy Hoy ${ }^{7}$, Basant Pawar ${ }^{8}$, Kirsty McKenzie ${ }^{4}$, Cherian T. Sajiv ${ }^{8}$, Peter Arrow ${ }^{9}$, Alex Brown ${ }^{10}$ and Lisa M. Jamieson ${ }^{1 *}$

\begin{abstract}
Background: Associations between kidney disease and periodontal disease are not well documented among Aboriginal people of Australia. The purpose of this investigation was to report and compare demographic, oral health, anthropometric and systemic health status of Aboriginal Australians with kidney disease and to compare against relevant Aboriginal Australians and Australian population estimates. This provides much needed evidence to inform dental health service provision policies for Aboriginal Australians with kidney disease.
\end{abstract}

Methods: Sample frequencies and means were assessed in adults represented in six datasets including: (1) 102 Aboriginal Australians with kidney disease residing in Central Australia who participated in a detailed oral health assessment; (2) 312 Aboriginal participants of the Northern Territory's PerioCardio study; (3) weighted estimates from 4775 participants from Australia's National Survey of Adult Oral Health (NSAOH); (4) Australian 2016 Census (all Australians); (5) National Health Survey 2017-2018 (all Australians) and; (6) Australian Health Survey: Biomedical Results for Chronic Diseases, 2011-2012 (all Australians). Oral health status was described by periodontal disease and experience of dental caries (tooth decay). Statistically significant differences were determined via non-overlapping 95\% confidence intervals.

Results: Aboriginal Australians with kidney disease were significantly older, less likely to have a tertiary qualification or be employed compared with both PerioCardio study counterparts and NSAOH participants. Severe periodontitis was found in 54.3\% of Aboriginal Australians with kidney disease, almost 20 times the $2.8 \%$ reported in NSAOH. A higher proportion of Aboriginal Australians with kidney disease had teeth with untreated caries and fewer dental restorations when compared to NSAOH participants. The extent of periodontal attachment loss and periodontal pocketing among Aboriginal Australians with kidney disease $(51.0 \%, 21.4 \%$ respectively) was several magnitudes greater than PerioCardio study $(22.0 \%, 12.3 \%$ respectively) and NSAOH (5.4\%, $1.3 \%$ respectively) estimates.

Conclusions: Aboriginal Australians with kidney disease exhibited more indicators of poorer oral health than both the general Australian population and a general Aboriginal population from Australia's Northern Territory. It is imperative that management of oral health among Aboriginal Australians with kidney disease be included as part of their ongoing medical care.

Keywords: Aboriginal Australian, Periodontal disease, Chronic kidney disease, End-stage kidney disease, Census, Population survey

\footnotetext{
*Correspondence: lisa.jamieson@adelaide.edu.au

${ }^{1}$ Australian Research Centre for Population Oral Health, Adelaide Dental

School, The University of Adelaide, Adelaide, Australia

Full list of author information is available at the end of the article
}

\section{Background}

Oral health is an important indicator of overall health and wellbeing [1]. Poor oral health can co-exist with many chronic conditions, such as diabetes and chronic kidney 
disease (CKD) [2-4]. Whilst the DMFT index provides an indicator of caries experience, its components can also be a useful proxy for access (or lack of access) to dental care and treatment received $[5,6]$.

Good oral health and provision of timely and appropriate dental services for Australians who have CKD and end-stage kidney disease (ESKD) is imperative, as pathology from the oral cavity contributes to overall inflammatory burden. Recent reports have shown the association of decline in kidney function and inflammation [7]. Furthermore, inflammation arising from periodontitis impedes glycaemic management in people who have diabetes [2]. Finally, optimal oral health which is free of infection is necessary for suitability for waitlisting for renal transplant [8]. Good oral health is especially essential for those undergoing renal transplantation, with transplantation inadvisable until all oral disease has been eradicated [9].

Both periodontal disease and untreated caries disproportionately affect Aboriginal Australians and people of lower socio-economic status [10]. Many reasons explain this inequity and include differences in access to affordable and timely dental care [11]. The maldistribution of dental practitioners to capital cities and major centres has a major impact on dental service availability and accessibility for those residing in regional or remote locations [12]. Nationally, $18 \%$ of Aboriginal Australians live in remote or very remote areas of Australia [13]. Although access to dental services in the Northern Territory is a priority for clients with dialysis-dependent ESKD across remote, regional and urban centres, this service need is often unmet.

The purpose of our study was to report demographic, oral health, anthropometric and systemic health status of Aboriginal Australians with kidney disease and to compare against relevant Aboriginal Australians and Australian population estimates. This new knowledge would inform current and future public health policy to mitigate oral health burden for Aboriginal Australians with kidney disease.

\section{Methods}

Data describing oral health among Aboriginal people with and without kidney disease (102 and 312 respectively) and the general population were derived from detailed research studies in the Northern Territory, and from four nationally representative health datasets. The study involving Aboriginal adults with kidney disease was based in two Central Australian locations in partnership with both government and private dialysis units, and government dental clinics. Study participants comprised patients aged over 18 years who had a history of CKD, including ESKD requiring dialysis. The study aims were to describe the extent and severity of periodontal disease among a group of Aboriginal adults with CKD and to examine the effects of a comprehensive periodontal intervention among an Aboriginal population with CKD [14]. Thirty-two Aboriginal Australians with kidney disease did not undergo an oral assessment due to coagulation risk or feeling unwell during the data collection phase. This meant that sociodemographic data was available for 102 Aboriginal adults with CKD, while clinical dental data was available for 70 . The first comparison was against 312 Aboriginal Australians without kidney disease who took part in the screening process for the PerioCardio study (based in Darwin, Katherine and Alice Springs). To be eligible for the PerioCardio study, participants needed to be aged $18+$ years and to have periodontal disease (ascertained from the screening). The aims of the PerioCardio study were to describe the extent and severity of measures of vascular health and inflammation in Aboriginal Australians with moderate or severe periodontal disease, to determine if there was a dose-response relationship between extent and severity of periodontal disease and measures of vascular health and inflammation, and to determine whether periodontal treatment influences vascular health and inflammation among Aboriginal Australians with moderate to severe periodontal disease [15]. Sociodemographic data was available for 312 PerioCardio study participants, while clinical dental data was available for 273. Other population-level comparisons included: (1) weighted estimates from 4,775 National Survey of Adult Oral Health 2004-2006 (NSAOH) participants [16]; (2) 2016 Australian Census data [17]; (3) National Health Survey (NHS) 2017-2018 [18] and; (4) Australian Health Survey (AHS): Biomedical Results for Chronic Diseases, 2011-2012 [19]. Across all six datasets we examined demographic, oral health and biomedical estimates.

\section{Oral assessment}

Oral assessments replicated the methods used in $\mathrm{NSAOH}$ [20]. Collected data included tooth presence, caries experience, periodontal destruction, gingival bleeding, dental plaque and calculus scores. A single caries experience score was recorded for each tooth using the following hierarchy: sound, filled due to caries, filled unsatisfactorily (defective restorations without decay), recurrent caries (new decay around existing filling) and decayed. Dental plaque and calculus were recorded for six teeth, which were the most anterior molar in each quadrant, in addition to the maxillary right central and mandibular left central incisors (if present) [21]. Periodontal probing depth (PPD) and gingival recession to calculate clinical attachment level (CAL) was measured at four sites of every tooth excluding third molars, which 
included the mesio-buccal, mid-buccal, disto-buccal and disto-palatal/lingual. 'Moderate' or 'severe' periodontal disease was determined by combining PPD and CAL based on the Centres for Disease Control and Prevention and the American Academy of Periodontology 2012 case definition [21]. Gingival bleeding on probing (BOP) was based on the established Gingival Index criteria [22].

\section{Other clinical measurements}

Height was measured to the nearest $0.1 \mathrm{~cm}$ using a portable stadiometer (Seca 213, Hamburg, Germany). Weight was measured to the nearest $0.1 \mathrm{~kg}$ using a portable weight scale (Tanita HD-351, Arlington Heights, USA) with participants lightly clothed. Body mass index (BMI) was calculated as weight (kg) divided by the square of height (m). Systolic and diastolic blood pressure was measured using the SphygmoCor XCEL device that automates measurement using a brachial cuff via three one-minute cuff inflation cycles, and central blood pressure estimated by use of a proprietary general transfer function (AtCor Medical, Sydney). Bilateral carotid intima-media thickness was asssessed by high-resolution ultrasound from a single angle of convenience from both left and right carotid arteries in the PerioCardio study [15], and from up to 3 angles per carotid artery in the study involving Aboriginal Australians with kidney disease.

\section{Statistical analysis}

All data were restricted to study participants aged between 18 and 80 years to reflect the age distribution in the sample of Aboriginal Australians with renal disease. Sample frequencies and means along with their respective $95 \%$ confidence intervals were generated to enable comparisons across datasets. Statistically significant differences were denoted by non-overlapping 95\% confidence intervals (CIs). Whenever there is a lack of overlap between 95\% CIs for two groups, it is a mathematical certainty that a hypothesis test of the difference between the same two groups would yield a P-value of less than 0.05 . In order to calculate the standard deviation of mean values reported in both the NHS and AHS from the standard error, the following formula was used: $\mathrm{SD}=S E \sqrt{ } N$. To account for differences in the number of teeth between study samples, extent scores using the methods described by Carlos and colleagues [21] were generated to permit comparisons of CAL, PPD and BOP. All analyses were performed using SAS 9.4 (Cary, NC, USA).

\section{Results}

Data were available for 102 Aboriginal Australians with renal disease; 85 with ESKD (83\%) and 17 non-ESKD (17\%). The average age was 48.1 years and the majority had achieved only up to a school education level (74.7\%) (Table 1). When comparing against other population estimates, the average age of Aboriginal Australians with kidney disease was significantly higher than participants enrolled in the PerioCardio study (41.0 years) and NSAOH (40.0 years) (Table 1). A higher proportion of Aboriginal Australians with kidney disease had completed school-only education and were unemployed or not seeking work when compared to PerioCardio study estimates (total proportion 46.3\%), NSAOH participants (total proportion $37.0 \%$ ) or the Australian population (total proportion 35.7\%). Most Aboriginal Australian participants with renal disease were unemployed (52.7\%) or not seeking work (33.3\%). The proportion of Aboriginal Australians with kidney disease who were current smokers was 38 percent. The proportion of Aboriginal Australians with kidney disease who were current smokers was half that of PerioCardio study participants. However, Aboriginal Australians with kidney disease were twice as likely to be current and half as likely to be former smokers compared to the Australian population and the NSAOH sample (Table 1).

Of the 70 Aboriginal Australians with kidney disease who provided clinical oral health data, almost all (92.9\%) had 'moderate' or 'severe' periodontitis. The estimate for 'moderate' or 'severe' periodontitis for Aboriginal Australians with kidney disease was significantly greater than the $25.9 \%$ in NSAOH. The prevalence of 'severe' periodontitis was two times higher among Aboriginal Australians with kidney disease (54.3\%) compared with the PerioCardio study participants (26.8\%) and almost 20 times higher than general Australian population estimates $(2.8 \%)$.

The mean number of teeth with untreated caries among Aboriginal Australians with kidney disease was 3.2 which was five times higher than that reported for $\mathrm{NSAOH}$ participants (0.6), but not significantly different to estimates from the PerioCardio study (3.0) (Table 2). Just over half had periodontal clinical attachment loss (CAL) of $4 \mathrm{~mm}$ or more. The extent of sites with periodontal pocket depth (PPD) of $4 \mathrm{~mm}$ or more was $21.4 \%$, while $31.9 \%$ experienced moderate or heavy bleeding on probing. Examining historical evidence of periodontal disease, Aboriginal Australians with kidney disease exhibited more than twice the number of sites with $C A L \geq 4 \mathrm{~mm}$ compared with PerioCardio participants $(22.0 \%)$; this was tenfold higher than that of national survey estimates of the Australian population (5.4\%). In reference to the presence of current disease, a two-fold difference in the extent of sites with $\mathrm{PPD} \geq 4 \mathrm{~mm}$ and 'moderate'/'heavy' bleeding on probing was seen between Aboriginal Australians with kidney disease and PerioCardio study participants (12.3\% and $16.0 \%$ respectively). 
Table 1 Socio-demographic characteristics of Aboriginal Australians with kidney disease in Central Australia compared with PerioCardio participants and other population estimates

\begin{tabular}{|c|c|c|c|c|}
\hline & $\begin{array}{l}\text { Aboriginal Australians with kidney disease } \\
\text { in Central Australia } \%(95 \% \mathrm{Cl})(\mathrm{N}=102)\end{array}$ & $\begin{array}{l}\text { PerioCardio study \% } \\
(95 \% \mathrm{Cl})(\mathrm{N}=312)\end{array}$ & $\begin{array}{l}\text { NSAOH } 2004-2006 \% \\
(95 \% \mathrm{Cl})(\mathrm{N}=4775)\end{array}$ & $\begin{array}{l}\text { Australian } \\
\text { population } \\
\text { estimates }{ }^{1,2}\end{array}$ \\
\hline Mean (SD) age* & $48.11(45.57,50.65)^{\dagger}$ & $40.01(38.87,41.15)^{\dagger}$ & $44.84(44.09,45.59)$ & - \\
\hline \multicolumn{5}{|l|}{$\operatorname{Sex}^{1}$} \\
\hline Female & $60.8(51.1,70.4)^{\dagger}$ & $44.2(38.7,49.8)^{\dagger}$ & $50.3(48.4,52.1)$ & 50.8 \\
\hline Male & $39.2(29.6,48.9)^{\dagger}$ & $55.8(50.2,61.3)^{\dagger}$ & $49.7(47.9,51.6)$ & 49.2 \\
\hline \multicolumn{5}{|c|}{ Highest school level completed ${ }^{1}$} \\
\hline Nil/primary & $30.3(20.6,40.1)^{\dagger}$ & $13.1(9.2,17.1)^{\dagger}$ & $2.3(1.8,2.8)^{\dagger}$ & 0.9 \\
\hline Years 8/9 & $32.6(22.7,42.5)$ & $20.8(16.1,25.5)$ & $6.9(6.0,7.8)^{\dagger}$ & 9.0 \\
\hline Years 10/11 & $22.5(13.6,31.3)^{\dagger}$ & $42.6(36.8,48.3)^{\dagger}$ & $30.8(29.0,32.7)$ & 29.6 \\
\hline Year 12 & $14.6(7.1,22.1)^{\dagger}$ & $23.5(18.6,28.4)$ & $60.0(57.9,62.1)^{\dagger}$ & 60.5 \\
\hline \multicolumn{5}{|c|}{ Post-school qualification } \\
\hline $\mathrm{Nil} / \mathrm{school}$ only & $74.7(65.6,83.8)^{\dagger}$ & $50.3(44.6,56.1)^{\dagger}$ & $36.8(34.8,38.8)^{\dagger}$ & 42.2 \\
\hline Trade/apprenticeship & $3.3(0.0,7.0)^{\dagger}$ & $5.5(2.9,8.2)$ & $14.1(12.7,15.4)^{\dagger}$ & $30.4^{\mathrm{b}}$ \\
\hline Certificate/diploma & $18.7(10.5,26.8)^{\dagger}$ & $33.4(28.0,38.9)^{\dagger}$ & $12.4(11.1,13.7)$ & \\
\hline University degree & $3.3(0.0,7.0)^{\dagger}$ & $10.7(7.1,14.3)^{\dagger}$ & $36.8(34.6,38.9)^{\dagger}$ & 27.4 \\
\hline \multicolumn{5}{|l|}{ Employment status ${ }^{1}$} \\
\hline $\operatorname{CDEP}^{* *}$ & $3.2(0.0,6.9)$ & $5.4(2.7,8.0)$ & - & - \\
\hline Full-time & $4.3(0.1,8.5)^{\dagger}$ & $42.3(36.5,48.1)^{\dagger}$ & $28.0(11.4,44.5)^{\dagger}$ & 42.4 \\
\hline Part-time & $6.5(1.4,11.5)$ & $6.1(3.3,8.9)$ & $35.0(18.2,51.8)$ & 21.9 \\
\hline Unemployed & $52.7(42.4,63.0)^{\dagger}$ & $6.5(3.6,9.4)^{\dagger}$ & $37.0(19.9,54.2)^{\mathrm{a}}$ & 4.5 \\
\hline $\begin{array}{l}\text { Not seeking work/retired/ } \\
\text { disability }\end{array}$ & $33.3(23.6,43.1)$ & $39.8(34.0,45.6)$ & & 31.2 \\
\hline \multicolumn{5}{|l|}{ Main source of income } \\
\hline Government benefits & $87.2(80.4,94.1)^{\dagger}$ & $21.2(16.4,26.1)^{\dagger}$ & $29.7(27.8,31.5)$ & - \\
\hline Wages/salary & $6.4(1.3,11.4)^{\dagger}$ & $46.0(40.1,51.9)^{\dagger}$ & $68.3(66.5,70.1)$ & - \\
\hline Student & - & $1.1(0.0,2.3)$ & $2.0(1.3,2.7)$ & - \\
\hline Other & $6.4(1.3,11.4)^{\dagger}$ & $31.7(26.2,37.2)^{\dagger}$ & - & - \\
\hline \multicolumn{5}{|l|}{ Smoking status ${ }^{2}$} \\
\hline Current & $38.4(27.9,48.9)^{\dagger}$ & $66.1(60.2,72.1)^{\dagger}$ & $17.0(15.5,18.6)^{\dagger}$ & $15.1(14.6,15.7)^{\dagger}$ \\
\hline Former & $12.8(5.6,20.0)^{\dagger}$ & $10.6(6.7,14.5)$ & $29.2(27.6,30.7)^{\dagger}$ & $29.2(28.5,29.8)^{\dagger}$ \\
\hline Never & $48.8(38.1,59.6)^{\dagger}$ & $23.3(17.9,28.6)^{\dagger}$ & $53.8(51.9,55.7)$ & $55.7(55.0,56.4)$ \\
\hline \multicolumn{5}{|l|}{ Chew tobacco } \\
\hline Yes & $21.7(13.2,30.3)^{\dagger}$ & $5.3(2.7,7.9)^{\dagger}$ & - & - \\
\hline No & $78.3(69.7,86.8)^{\dagger}$ & $94.7(92.1,97.3)^{\dagger}$ & - & - \\
\hline \multicolumn{5}{|c|}{ Standard alcohol drinks/week ${ }^{2}$} \\
\hline None & $56.6(45.2,68.0)^{\dagger}$ & $36.4(30.6,42.2)^{\dagger}$ & - & $43.9(43.2,44.7)^{\dagger}$ \\
\hline $1-7$ drinks & $27.6(17.3,37.9)$ & $33.1(27.5,38.7)$ & - & $38.9(38.2,39.6)$ \\
\hline 8-19 drinks & $6.6(0.9,12.3)$ & $11.0(7.3,14.8)$ & - & $6.3(6.0,6.7)$ \\
\hline 20 or more & $9.2(2.6,15.9)$ & $19.5(14.7,24.2)$ & - & $9.8(9.4,10.2)$ \\
\hline \multicolumn{5}{|l|}{ Periodontal case status\# } \\
\hline Non-case or mild & $7.1(1.0,13.3)^{\dagger}$ & $12.6(8.9,16.3)$ & $74.1(72.3,75.9)^{\dagger}$ & - \\
\hline Moderate & $38.6(26.9,50.3)^{\dagger}$ & $60.6(55.2,66.1)^{\dagger}$ & $23.1(21.5,24.7)^{\dagger}$ & - \\
\hline Severe & $54.3(42.3,66.2)^{\dagger}$ & $26.8(21.8,31.7)^{\dagger}$ & $2.8(2.2,3.4)^{\dagger}$ & - \\
\hline
\end{tabular}

\footnotetext{
2016 Australian Census (limited to 18-80 years of age)

${ }^{2}$ National Health Survey First Results 2017-2018 (18+years of age)

${ }^{*}$ Mean $(95 \% \mathrm{Cl})$ reported

** Community Development Employment Project, a government-initiated employment scheme

\# CDC-AAP 2007 case definition

a Proportion around $95 \% \mathrm{Cl}$ from PerioCardio study combines unemployed, not seeking work, retired, disability
} 
Table 1 (continued)

b Proportion from 2016 Australian Census combines Trades, apprenticeship, certificate and vocational diploma

${ }^{\dagger}$ denotes non-overlapping 95\% confidence intervals

Table 2 Oral health parameters of Aboriginal Australians with kidney disease in Central Australia compared with PerioCardio participants and Australian population estimates

\begin{tabular}{|c|c|c|c|}
\hline & $\begin{array}{l}\text { Aboriginal Australians with kidney } \\
\text { disease in Central Australia } \\
\text { mean }(95 \% \mathrm{CI})(\mathrm{N}=70)\end{array}$ & $\begin{array}{l}\text { PerioCardio study mean }(95 \% \\
\mathrm{Cl})(\mathrm{N}=273)\end{array}$ & $\begin{array}{l}\text { NSAOH } 2004-2006 \\
\text { mean }(95 \% \mathrm{Cl}) \\
(\mathrm{N}=4,775)\end{array}$ \\
\hline Number of teeth & $24.34(22.89,25.79)^{\dagger}$ & $26.50(25.86,27.14)^{\dagger}$ & $25.59(25.38,25.79)$ \\
\hline Number of decayed teeth & $3.17(2.47,3.87)^{\dagger}$ & $3.02(2.64,3.40)$ & $0.59(0.53,0.66)^{\dagger}$ \\
\hline Number of missing teeth & $6.40(4.92,7.88)^{\dagger}$ & $3.83(3.22,4.44)^{\dagger}$ & $4.92(4.68,5.17)$ \\
\hline Number of filled teeth & $1.29(0.81,1.76)^{\dagger}$ & $2.87(2.46,3.28)^{\dagger}$ & $8.49(8.21,8.78)^{\dagger}$ \\
\hline DMFT & $10.86(9.20,12.51)^{\dagger}$ & $9.72(8.88,10.56)$ & $14.01(13.60,14.42)^{\dagger}$ \\
\hline Mean pocket depth & $2.82(2.63,3.01)^{\dagger}$ & $2.32(2.25,2.38)^{\dagger}$ & - \\
\hline Extent $\mathrm{AL} \geq 4 \mathrm{~mm}(\%)$ & $51.03(42.87,59.19)^{\dagger}$ & $21.96(19.42,24.50)^{\dagger}$ & $5.37(4.93,5.82)^{\dagger}$ \\
\hline Extent PPD $\geq 4 \mathrm{~mm}(\%)$ & $21.38(16.14,26.62)^{\dagger}$ & $12.26(10.74,13.79)^{\dagger}$ & $1.31(1.03,1.59)^{\dagger}$ \\
\hline Extent PPD $\geq 6$ mm (\%) & $3.48(0.82,6.14)$ & $1.15(0.82,1.48)$ & - \\
\hline Extent $\mathrm{AL} \geq 3 \mathrm{~mm} \& \mathrm{PPD} \geq 4 \mathrm{~mm}(\%)$ & $20.49(15.41,25.56)^{\dagger}$ & $12.10(10.59,13.61)^{\dagger}$ & $1.20(1.02,1.38)^{\dagger}$ \\
\hline Extent index sites with calculus (\%) & $88.61(82.98,94.24)$ & - & - \\
\hline $\begin{array}{l}\text { Extent index sites with 'moderate'/ 'heavy' } \\
\text { plaque }(\%)^{*}\end{array}$ & $79.39(70.65,88.14)$ & - & - \\
\hline Extent'moderate'/'heavy' BOP (\%) & $31.93(21.45,42.40)^{\dagger}$ & $16.01(13.94,18.09)^{\dagger}$ & - \\
\hline
\end{tabular}

* six index sites examined

DMFT: mean number of decayed, missing and filled teeth

AL: attachment loss

PPD: periodontal pocket length

BOP: bleeding on probing

${ }^{\dagger}$ denotes non-overlapping $95 \%$ confidence intervals

The mean systolic blood pressure of Aboriginal Australians with renal disease was $143 \mathrm{mmHg}$, significantly higher than estimates from both the general Australian population $(123 \mathrm{mmHg}$ ) and from the PerioCardio study (125 mmHg) (Table 3). Mean HbA1c was higher among Aboriginal Australians with kidney disease $(54.4 \mathrm{mmol} / \mathrm{mol})$ compared with national estimates (36.2 $\mathrm{mmol} / \mathrm{mol}$; data on HbA1c in national samples stratified by diabetes not available), and estimates from the PerioCardio study $(45.0 \mathrm{mmol} / \mathrm{mol})$ although the 95\% confidence intervals overlapped. The mean total cholesterol of Aboriginal Australians with renal disease was $4.05 \mathrm{mmol} / \mathrm{L}$, while the mean total cholesterol to high-density lipoprotein ratio was 5.5. Whilst the total cholesterol of Aboriginal Australians with kidney disease was significantly lower than both PerioCardio participants $(5.0 \mathrm{mmol} / \mathrm{L})$ and Australian estimates $(5.1 \mathrm{mmol} / \mathrm{L})$, the total cholesterol to high-density lipoprotein ratio was significantly higher among Aboriginal Australians with kidney disease when compared to Australian estimates (3.7).

\section{Discussion}

This investigation highlights stark differences in the oral health of Aboriginal Australians with kidney disease in terms of periodontal disease and dental caries when compared with estimates from both the general Australian population and against another sample of Aboriginal Australian adults from the Northern Territory. Of Aboriginal Australians with kidney disease who were screened, only $7.5 \%$ did not have moderate or severe periodontal disease, and the prevalence of those with severe periodontal disease was 20 times that reported for the general Australian population. While we expected periodontal disease to be more prevalent and more severe among people with kidney disease [23], the magnitude of poorer oral health among adults with CKD was striking.

Others have cited high prevalence of periodontal disease among CKD and ESKD patients. In Romania, Vessia and colleagues reported that among 101 hemodialysis patients with ESKD (mean age 53 years), estimates of periodontal disease, calculus index and bleeding on probing were on par with those reported in our study [24]. In 
Table 3 Anthropometric and biomedical characteristics of Aboriginal Australians with kidney disease in Central Australia compared to PerioCardio participants and Australian population estimates

\begin{tabular}{|c|c|c|c|}
\hline & $\begin{array}{l}\text { Central Australian Aboriginal Australians } \\
\text { with kidney disease mean }(95 \% \mathrm{Cl})(\mathrm{N}=102)\end{array}$ & $\begin{array}{l}\text { PerioCardio study mean } \\
(95 \% \mathrm{Cl})(\mathrm{N}=273)\end{array}$ & $\begin{array}{l}\text { Australian } \\
\text { population estimates } \\
(95 \% \mathrm{Cl})^{1,2}\end{array}$ \\
\hline Weight (kg) & $81.41(75.49,87.32)$ & $84.17(81.62,86.71)$ & $79.40(78.81,79.99)$ \\
\hline Body mass index ${ }^{1}$ & $29.20(26.91,31.48)$ & $29.16(28.29,30.02)$ & $28.10(27.46,28.75)$ \\
\hline Waist to hip ratio & $0.97(0.94,1.00)$ & $0.94(0.93,0.95)$ & - \\
\hline Sitting systolic BP $(\mathrm{mmHg})^{1}$ & $143(136,151)^{\dagger}$ & $125(123,127)$ & $123(122,123)$ \\
\hline Sitting diastolic BP $(\mathrm{mmHg})^{1}$ & $85(80,89)^{\dagger}$ & $80(79,81)$ & $77(77,77)$ \\
\hline Max. carotid intima-media thickness & $0.80(0.70,0.90)$ & $0.86(0.82,0.89)$ & - \\
\hline $\mathrm{HbA} 1 \mathrm{c}(\mathrm{mmol} / \mathrm{mol})^{2}$ & $54.42(46.04,62.81)^{\dagger}$ & $44.97(42.95,46.99)$ & $36.20(35.81,36.59)$ \\
\hline $\mathrm{eGFR}\left(\mathrm{mL} / \mathrm{min} / 1.73 \mathrm{~m}^{2}\right)^{2}$ & $32.62(17.79,47.45)^{\dagger}$ & - & $85.50(85.30,85.70)$ \\
\hline Urine albumin & $1,364.31(24.91,2,703.71)$ & $41.92(18.71,65.13)$ & - \\
\hline Urine creatinine & $10.05(5.95,14.14)$ & $7.92(7.15,8.69)$ & - \\
\hline Urine albumin-creatinine ratio $(\mathrm{mg} / \mathrm{g})^{2}$ & $250.19(19.86,480.52)^{\dagger}$ & $7.26(3.74,10.78)$ & $2.2(-16.03,20.43)$ \\
\hline Total cholesterol $(\mathrm{mmol} / \mathrm{L})^{2}$ & $4.05(3.66,4.44)^{\dagger}$ & $4.98(4.85,5.12)$ & $5.1(4.51,5.69)$ \\
\hline Triglycerides $(\mathrm{mmol} / \mathrm{L})^{2}$ & $2.43(1.90,2.96)$ & $2.53(2.30,2.76)$ & $1.3(-0.66,3.26)$ \\
\hline HDL cholesterol $(\mathrm{mmol} / \mathrm{L})^{2}$ & $0.82(0.70,0.94)^{\dagger}$ & $1.04(1.00,1.08)$ & $1.3(0.52,2.08)$ \\
\hline LDL cholesterol $(\mathrm{mmol} / \mathrm{L})^{2}$ & $2.16(1.86,2.45)^{\dagger}$ & $2.91(2.78,3.04)$ & $3.1(2.32,3.88)$ \\
\hline Total/HDL cholesterol ratio ${ }^{2}$ & $5.48(4.69,6.27)$ & $5.22(4.98,5.45)$ & $3.73(2.95,4.51)$ \\
\hline
\end{tabular}

${ }^{1}$ National Health Survey First Results 2017-2018, 4364.0.55.001 (participants 18 + years of age)

2 Australian Health Survey: Biomedical Results for Chronic Diseases, 2011-12, 4364.0.55.005 (participants 18 + years of age)

Australian Health Survey 2017-2018: https://www.abs.gov.au/AUSSTATS/abs@.nsf/DetailsPage/4364.0.55.0012017-18?OpenDocument

95\% Cl calculator for mean: https://www.socscistatistics.com/confidenceinterval/default2.aspx SE converter for SD: https://handbook-5-1.cochrane.org/chapt er_7/7_7_3_2_obtaining_standard_deviations_from_standard_errors_and.htm

${ }^{+}$Denotes non-overlapping $95 \%$ confidence intervals

a review of periodontal disease among patients receiving dialysis, Miyata and colleagues reported that periodontal diseases affected inflammation, the immune response, and nutritional status of patients on dialysis, with the severity of periodontal disease being significantly associated with CRP, albumin, IL- 6 and TNF- $\alpha$ [25]. The authors demonstrated how dialysis exacerbates oral conditions via disruption of salivary characteristics (mainly $\mathrm{pH}$ and flow rate) which, in turn, contributes to severity of periodontal disease. They concluded that treatment and maintenance of oral health are important for quality of life, prevention of pathological conditions and prolongation of survival among dialysis patients.

It is important to discuss inequity in relation to access to preventive health care (including dental health care) in the context of our findings. Aboriginal Australians with kidney disease were older, resided in a remote location, had attained a lower level of formal education, were less likely to be employed, and more likely to be receiving government benefits as their main source of income when compared with other populations included in this study. Indeed, our group has previously reported the association between indicators of CKD and disadvantage [26], and there is a regional variation in CKD among the wider Australian population [27]. People with end-stage kidney disease require either haemodialysis, peritoneal dialysis or a kidney transplant to survive [28]. The majority of Aboriginal Australians with kidney disease in our sample undergo haemodialysis in thrice-weekly sessions lasting up to five hours. Under these circumstances, engaging in regular employment can be challenging due to co-existing health conditions, and thus financial support with government benefits was not unexpected. In a study involving 2,914 adults with moderate-to-severe CKD across 14 countries, Morton and colleagues showed how $32 \%$ were living in relative poverty, defined as having a household income $<50 \%$ of country median income, at study commencement. Amongst those not living in relative poverty at study commencement, $22 \%$ were living in poverty by study end 5 years later [29]. The authors concluded that progression of CKD is associated with increased odds of falling into poverty, with kidney transplantation being a potential mitigating factor against this. In relation to our findings, poverty among Aboriginal Australians with kidney disease likely contributes to the many challenges they may face in seeking and receiving timely dental care. 
We also report differences in tooth loss among Aboriginal people of the Northern Territory with and without kidney disease. Tooth loss is the end-point of periodontal disease, equivalent to amputation in medicine. Consequently, loss of teeth eliminates the previous history of periodontal disease (and caries), but also serves to underestimate oral disease experience [30]. The extent of PPD, CAL and BOP findings presented in Table 2, which account for tooth loss, indicates that the number of areas throughout the mouths of Aboriginal Australians with kidney disease affected by periodontal disease is double that of the PerioCardio study participants. The NSAOH estimated in 2007 that approximately 30\% of Aboriginal adults had periodontal disease [16]. Several observational studies involving Aboriginal people in urban and remote locations all posit that periodontal disease is much more common than in the non-Aboriginal Australian population $[31,32]$.

Cigarette smoking was attributed to 38.5 million cases of periodontal disease globally in 2015 [33]. Australian estimates from NSAOH reported that smoking contributed to 700,000 cases of 'moderate' or 'severe' periodontal disease [34]. The key mechanism by which cigarette smoking or tobacco chewing causes periodontal disease is by interfering with vascular and immunologic reactions, as well as by undermining the supportive functions and wound healing capabilities of the periodontal tissues [35]. The prevalence of cigarette smoking has steadily decreased in Australia in response to strict tobacco legislation and a raft of measures including marked increases in taxation and plain packaging laws [36]. This key public health policy has contributed to an $8.6 \%$ reduction in smoking rates among Aboriginal Australian adults from $50 \%$ in 2004 to $41.4 \%$ in 2015 [37]. In this light, the frequency of current smokers among Aboriginal Australians with kidney disease at $32.5 \%$ is lower than the latest Aboriginal Australian population estimate; however, exposure to tobacco in our sample was offset with almost 1-in-5 reporting they regularly chewed tobacco. This is consistent with previous Central Australian data and reflects differences between the Central Australia regions and Top End (hence between the Aboriginal Australians with kidney disease and PerioCardio study estimates) [38]. Whilst tobacco use is a major cardiovascular disease (CVD) risk factor, and CVD a major co-morbid condition of adults with $C K D$, we are unaware of reports describing successful smoking cessation among Aboriginal adults with CVD and/or CKD.

Untreated caries is a major contributor to dental pain affecting mastication (chewing), which directly affects dietary choices, malnutrition risk and quality of life [39]. Periodontal disease is not usually painful unless abscesses develop. However, periodontal disease does impact on quality of life through loss of function and aesthetics [40]. In this study, there was a higher amount of untreated caries, and lower number of filled teeth among Aboriginal Australians with kidney disease compared with both PerioCardio and NSAOH participants. Both indicators (caries and filled teeth) may reflect individual-level dental seeking behaviours or oral health services accessibility. Combined with the higher mean number of missing teeth, we speculate that among this sample of Aboriginal Australians with kidney disease there was a high level of oral health seeking behaviour for management (tooth extraction), which is consistent with other studies involving Aboriginal Australians [41-43]. It is worth noting that inadequate access to health services for Aboriginal Australians with kidney disease is not limited to dental services. Morton and colleagues demonstrated in a systematic review among adults with moderate-tosevere CKD, that socially disadvantaged pre-dialysis and dialysis patients experience poorer access to specialist cardiovascular health services, higher rates of cardiovascular events and mortality than their more advantaged counterparts [44].

The most significant relevant bias relates to the different designs of the included studies: the study involving Aboriginal Australians with kidney disease and the PerioCardio study were both convenience studies, while the four other datasets were representative, populationlevel surveys (with weighted estimates) or the Census. Potential participants for both the study involving Aboriginal Australians with kidney disease and the PerioCardio study were invited to be involved in a periodontal health project, which clearly caused selection bias with the samples thus not being representative. In both studies, there was no dental pre-screening done by those who referred potential participants to the study team. There have not been any truly population-representative studies reporting oral health and prevalence of periodontal disease among the Aboriginal Australian population, especially the population with kidney disease. We recommend additional research to report this.

In this observational study, we report poorer oral health status of Aboriginal Australians with kidney disease than the general Australian population, but also compared with other Aboriginal Australian adults living in the Northern Territory. Because of the profound health impacts and reduced quality of life associated with untreated periodontal disease and dental caries, the findings reinforce the importance of making and keeping oral health a priority action area for all people with kidney disease. 


\section{Conclusions}

Aboriginal Australians with kidney disease exhibited more indicators of poorer oral health than both the general Australian population and a general Aboriginal population from Australia's Northern Territory. It is imperative that management of oral health among Aboriginal Australians with kidney disease be included as part of their ongoing medical care.

\begin{abstract}
Abbreviations
NSAOH: National Survey of Adult Oral Health; DMFT: decayed, missing and filled teeth; CKD: chronic kidney disease; ESKD: end-stage kidney disease; NHS: National Health Survey; AHS: Australian Health Survey; PPD: periodontal pocket depth; CAL: clinical attachment loss; BOP: bleeding on probing; BMI: body mass index; Cl: confidence interval; SD: standard deviation; se: standard error; HbA1c: glycosylated haemoglobin; CRP: C-reactive protein; IL-6: InterLeukin 6; TNF: tumour necrosis factor; CVD: cardio vascular disease.
\end{abstract}

\section{Acknowledgements}

The authors gratefully acknowledge the support of study participants, study staff, Central Australian Renal Health services, Fresenius Medical Care, Northern Territory Oral Health Services, Purple House in Alice Springs and other key stakeholder groups in Central Australia.

\section{Author contributions}

Study concept: LJ, CS, AC, LMB, MS, KK, PA, LA, DH, JH, AB. Study design: $L$, CS, AC, LMB, MS, KK, PA, LA, DH, JH, AB. Data collection: LJ, CS, MS, KK, KM. Data analysis: $L J, K K$. Drafting of the reporting: $L J, A C, L M B, K K, P A, D H, J H, K M$. Reviewing manuscript for intellectual content: $L J, C S, A C, L M B, M S, K K, B P, P A$, $L A, W H, D H, J H, K M, A B$. All authors (LJ, CS, AC, LMB, MS, KK, BP, KM, PA, LA, WH, $\mathrm{DH}, \mathrm{AB}, \mathrm{JH}$ ) agreed on the final paper for publication. All authors read and approved final manuscript.

\section{Funding}

The PerioCKD study was funded by the National Health and Medical Research Council: project grant APP1078077. LMJ was supported by a NHMRC Senior Research Fellowship 1102587. JH acknowledges funding by NHMRC Fellowship 1092576 and 1174758. LMB was funded by NHMRC Practitioner Fellowship 1078477 and KK was funded by an NHMRC Early Career Fellowship APP1113098. MRS was supported by a National Heart Foundation of Australia Future Leader Fellowship (100419). The funding body played no role in the design of the study, the collection, analysis, and interpretation of data and or of the writing of the manuscript.

\section{Availability of data and materials}

Available from corresponding author upon request.

\section{Consent for publication}

Not applicable.

\section{Ethics approval and consent to participate}

Ethics approval obtained from the University of Adelaide Human Research Ethics Committee and the Central Australian Human Research Ethics Committee. All participants provided written informed consent.

\section{Competing interests}

The authors declare there are no competing interests.

\section{Author details}

${ }^{1}$ Australian Research Centre for Population Oral Health, Adelaide Dental School, The University of Adelaide, Adelaide, Australia. ${ }^{2}$ Wellbeing and Preventable Chronic Disease Division, Menzies School of Health Research, Charles Darwin University, Darwin, Australia. ${ }^{3}$ Department of Nephrology, Division of Medicine, Royal Darwin Hospital, Darwin, Australia. ${ }^{4}$ Boden Collaboration for Obesity, Nutrition, Exercise and Eating Disorders, Faculty of Medicine and Health, The University of Sydney, Sydney, Australia. ${ }^{5}$ Department of Renal Medicine, Westmead Centre for Medical Research, Westmead Hospital,
University of Sydney, Westmead, Australia. ${ }^{6}$ NHMRC Clinical Trials Centre, University of Sydney, Sydney, Australia. ${ }^{7}$ Griffith University, Brisbane, Australia.

${ }^{8}$ NT Government, Darwin, Australia. ${ }^{9}$ WA Government, Perth, Australia.

${ }^{10}$ South Australian Health and Medical Research Institute, Adelaide, Australia.

Received: 26 August 2020 Accepted: 28 January 2021

Published online: 04 February 2021

\section{References}

1. Peres MA, Macpherson LMD, Weyant RJ, Daly B, Venturelli R, Mathur MR, Listl S, Celeste RK, Guarnizo-Herreño CC, Kearns C, Benzian H, Allison P, Watt RG. Oral diseases: a global public health challenge. Lancet. 2019:394:249-60.

2. Chapple ILC, Genco R, Working Group 2 of the Joint EFP \& AAP Workshop Diabetes and periodontal diseases: consensus report of the Joint EFP/ AAP Workshop on Periodontitis and Systemic Diseases. J Clin Periodontol. 2013:40:S106-S12.

3. Linden GJ, Herzberg MC. Periodontitis and systemic diseases: a record of discussions of working group 4 of the Joint EFP/AAP Workshop on Periodontitis and Systemic Diseases. J Clin Periodontol. 2013;40:S20-3.

4. Schenkein HA, Loos BG. Inflammatory mechanisms linking periodontal diseases to cardiovascular diseases. J Clin Periodontol. 2013;40:551-69.

5. Selwitz R, Ismail A, Pitts N. Dental caries. Lancet. 2007;369:51-9.

6. World Health Organisation. Oral health surveys: basic methods - . 5th ed. Geneva: World Health Organisation; 2013.

7. Barr EL, Barzi F, Hughes JT, Jerums G, O'Dea K, Brown AD, Ekinci El, Jones GR, Lawton PD, Sinha A, Maclsaac RJ, Cass A, Maple-Brown LJ. Contribution of cardiometabolic risk factors to estimated glomerular filtration rate decline in Indigenous Australians with and without albuminuria - the eGFR Follow-up Study. Nephrology. 2018;23:682-9.

8. Chadban SJ, Wu H, Hughes J. Macrophages and kidney transplantation. Semin Nephrol. 2010;30:278-89.

9. Reyes U, Spolarich AE, Han PP. A comprehensive oral preventive care protocol for caring for the renal transplant population. J Dent Hyg. 2016;90:88-99.

10. Roberts-Thomson K, Do L. Oral Health Status. In: Slade G, Spencer A, Roberts-Thomson K, editors. Australia's dental generations: the National Survey of Adult Oral Health 2004-06. Dental Statistics and Research Series No. 34. Canberra: Australian Institute of Health and Welfare 2007. p. 119.

11. Harford J, Spencer A, Roberts-Thomson K. Oral Health. In: The Health of Indigenous Australians. South Melbourne, Australia: Oxford University Press; 2003. 26 p.

12. Balasubramanian $M$, Teusner D. Dentists specialists and allied practitioners in Australia: dental labour force collection, 2006 Canberra. Australia: Australian Institute of Health and Welfare; 2011.

13. Australian Bureau of Statistics. Census counts by indigenous status, by usual residence and place of enumeration-Remoteness areas, 2016. Canberra: Australian Bureau of Statistics; 2018.

14. Jamieson L, Skilton M, Maple-Brown L, Kapellas K, Askie L, Hughes J, et al. Periodontal disease and chronic kidney disease among Aboriginal adults; an RCT. BMC Nephrol. 2015:16.

15. Kapellas K, Maple-Brown LJ, Jamieson LM, Do LG, O’Dea K, Brown A, et al. Effect of periodontal therapy on arterial structure and function among Aboriginal Australians: a randomized. Control Trial Hypertens. 2014;64:702-8

16. Slade G, Spencer A, Roberts-Thomson K. Australia's dental generations: the National Survey of Adult Oral Health 2004-06. 2007.

17. Australian Bureau of Statistics. 2016 Census Canberra: Australian Bureau of Statistics; 2017 [updated 11/4/2017. Available from: https://www.abs. gov.au/websitedbs/censushome.nsf/home/2016.

18. Australian Bureau of Statistics. 4364.0.55.001 - National Health Survey: First Results, 2017-18 Canberra: Australian Bureau of Statistics,; 2018 [updated 12/12/2018. Available from: https://www.abs.gov.au/AUSSTATS/ abs@.nsf/DetailsPage/4364.0.55.0012017-18?OpenDocument.

19. Australian Bureau of Statistics. National Health Survey: Biomedical Results for Chronic Diseases, 2012-2013 Australia. Canberra: Australian Bureau of Statistics; 2013. 
20. Slade G, Roberts-Thomson K, Ellershaw A. Survey Aims and Methods. In: In: Slade G, Spencer AJ, Roberts-Thomson KF. (Editors). editor. Australia's Dental Generations: The National Survey of Adult Oral Health 2004-2006. AlHW cat. no. DEN 165. Canberra: Australian Institute of Health and Welfare; 2007. p. 11-36.

21. Löe $H$. The Gingival Index, the Plaque Index and the Retention Index Systems. J Periodontol. 1967;38:610-6.

22. Eke PI, Page RC, Wei L, Thornton-Evans G, Genco RJ. Update of the case definitions for population-based surveillance of periodontitis. J Periodontol. 2012:83:1449-54.

23. Carlos J, Wolfe M, Kingman A. The extent and severity index: a simple method for use in epidemiologic studies of periodontal disease. J Clin Periodontol. 1986;13:500-5.

24. Kapellas K, Singh A, Bertotti M, Nascimento G, Jamieson LM, On Behalf of the Perio CKD collaboration. Periodontal and chronic kidney disease association: a systematic review and meta-analysis. Nephrology. 2019;24:202-12.

25. Veisa G, Tasmoc A, Nistor I, Segall L, Siriopol D, Solomon SM, Donciu MD, Voroneanu L, Nastasa A, Covic A. The impact of periodontal disease on physical and psychological domains in long-term hemodialysis patients: a cross-sectional study. Int Urol Nephrol. 2017;49:1261-6.

26. Miyata Y, Obata Y, Mochizuki Y, Kitamura M, Mitsunari K, Matsuo T, Ohba K, Mukae H, Nishino T, Yoshimura A, Sakai H. Periodontal disease in patients receiving dialysis. Int J Mol Sci. 2019;20.

27. Ritte RE, Lawton P, Hughes JT, Barzi F, Brown A, Mills P, Hoy W, O'Dea K, Cass A, Maple-Brown L. Chronic kidney disease and socio-economic status: a cross sectional study. Ethn Health. 2020;25:93-109.

28. Australian Institute of Health and Welfare. Geographical variation in chronic kidney disease. Canberra: AlHW; 2017.

29. Kidney Health Australia. Dialysis South Melbourne2019 [Available from: https://kidney.org.au/your-kidneys/support/kidney-disease/treatment/ dialysis

30. Morton RL, Schlackow I, Gray A, Emberson J, Herrington W, Staplin N, Reith C, Howard K, Landray MJ, Cass A, Baigent C, Mihaylova B; SHARP Collaborative Group. Impact of CKD on Household Income. Kidney Int Rep. 2018;3:610-618.

31. Kapellas K, Skilton M, Maple-Brown L, Do L, Bartold P, O'Dea K, et al. Periodontal disease and dental caries among Indigenous Australians living in the Northern Territory, Australia. Aust Dental J. 2014;59:93-9.

32. Kruger E, Smith K, Atkinson D, Tennant M. The oral health status and treatment needs of Indigenous adults in the Kimberley region of Western Australia. Aust J Rural Health. 2008:16:283-9.

33. Roberts-Thomson K, Do L, Bartold P, Daniels J, Grosse A, Meihubers S. Prevalence, extent and severity of severe periodontal destruction in an urban Aboriginal and Torres Strait Islander population. Aust Dent J. 2014;59:43-7.

34. Schwendicke F, Dörfer CE, Meier T. Global smoking-attributable burden of periodontal disease in 186 countries in the year 2015. J Clin Periodontol. 2018:45:2-14.

35. Ju X. Periodontal disease, tooth loss and daily life in older adults in South Australia: a longitudinal study. Adelaide: The University of Adelaide; 2016. PhD Dissertation http://hdl.handle.net/2440/100195

36. Bergström J. Tobacco smoking and chronic destructive periodontal disease. Odontology. 2004;92:1-8.

37. Do L, Slade G, Roberts-Thomson K, Sanders A. Smoking-attributable periodontal disease in the Australian adult population. J Clin Periodontol. 2008;35:398-404

38. Lovett R, Thurber K, Wright A, Maddox R, Banks E. Deadly progress: changes in Australian Aboriginal and Torres Strait Islander adult daily smoking, 2004-2015. Public Health Res Pract. 2017;27:e2741733.

39. Ratsch A, Steadman KJ, Bogossian F. The pituri story: a review of the historical literature surrounding traditional Australian Aboriginal use of nicotine in Central Australia. J Ethnobiol Ethnomed. 2010;6:26.

40. Allen PF. Assessment of oral health related quality of life. Health Qual Life Outcomes. 2003;1:40.

41. Ferreira MC, Dias-Pereira AC, Branco-de-Almeida LS, Martins CC, Paiva SM. Impact of periodontal disease on quality of life: a systematic review. J Periodontal Res. 2017;52:651-65.

42. Amarasena N, Kapellas K, Skilton MR, Maple-Brown LJ, Brown A, Bartold $M$, et al. Factors associated with routine dental attendance among Aboriginal Australians. J Health Care Poor Underserved. 2016;27:67-80.

43. Smith K, Kruger E, Dyson K, Tennant M. Oral health in rural and remote Western Australian Indigenous communities: a two-year retrospective analysis of 999 people. Int Dent J. 2007;57:93-9.

44. Slater PJ. Patterns of access to Public oral health care in Queensland by gender, indigenous status and rurality. Aust Dent J. 2001;46:122-33.

45. Morton RL, Schlackow I, Mihaylova B, Staplin ND, Gray A, Cass A. The impact of social disadvantage in moderate-to-severe chronic kidney disease: an equity-focused systematic review. Nephrol Dial Transpl. 2016:31:46-56

\section{Publisher's Note}

Springer Nature remains neutral with regard to jurisdictional claims in published maps and institutional affiliations.
Ready to submit your research? Choose BMC and benefit from:

- fast, convenient online submission

- thorough peer review by experienced researchers in your field

- rapid publication on acceptance

- support for research data, including large and complex data types

- gold Open Access which fosters wider collaboration and increased citations

- maximum visibility for your research: over 100M website views per year

At BMC, research is always in progress.

Learn more biomedcentral.com/submissions 